\title{
АНАЛИЗ СОВРЕМЕННОГО СОСТОЯНИЯ И ПЕРСПЕКТИВЫ РАЗВИТИЯ КОНКУРЕНТНОЙ БОРЬБЫ НА СТРАХОВОМ РЫНКЕ РОССИИ
}

\author{
A.B. CEMËHOBA \\ канд. экон. наук, доц. \\ Санкт-Петербургский государственный \\ университет сервиса и экономики
}

\begin{abstract}
Аннотация:
В статье проведен анализ современного состояния страхового рынка России, рассмотрена динамика концентрации страхового рынка, перераспределение долей основных участников рынка страхования по годам, приведены экспертные мнения относительно состояния и перспектив развития рынка страхования и конкурентной борьбы участников рынка.

Ключевые слова: страхование, рынок страховых услуг, экспертиза страхового рынка, концентрация страхового рынка, динамика концентрации страхового рынка, конкурентная борьба.
\end{abstract}

\section{ВВЕДЕНИЕ}

Любое современное предприятие, осуществляющее свою деятельность в условиях непрерывной трансформации политических, экономических, социальных и демографических факторов общества, постоянно ощущает на себе не только интенсивную динамику этих изменений, но и чувствует острую необходимость своевременной и адекватной реакции на эти изменения. Буквально все области общественной жизни от политических и предпринимательских до культурных сообществ вынуждены сегодня вкладывать в основу своего существования не только приобретенные знания, опыт и навыки выживания, но и мощную интуицию, прогнозирование и предвидение результатов изменений в той или иной области общественной жизни, а также поддерживать столь необходимую и все нарастающую скорость реакции на происходящие во внешней среде изменения. Это является плацдармом для мониторинга политической и экономической ситуации в стране, а также в предпринимательской сфере, в том числе на конкретных рынках, с целью активизации научного, производственного и финансового потенциала компаний для усиления позиций на рынке и развития предприятия.

Все это свидетельствует об усилении конкурентной борьбы предприятий во всех сферах бизнеса, особенно в сфере услуг. Сфера услуг относится к важнейшим видам деятельности, связанным с функционированием и развитием всех отраслей экономики, удовлетворением жизненно важных потребностей человека. С точки зрения экспертов в данной области, современное состояние сферы услуг может свидетельствовать о ее недостаточной готовности своевременно реагировать на изменяющиеся потребности рынка и состоятельности в 
определении вектора направления изменений, способствующим улучшению бизнес-процессов [3]. Будучи крупной социально - экономической системой, она морально устарела, так как была разработана в советский период, но во времена перестройки она начала подвергаться реструктуризации, которая до сих пор продолжается, но с учетом интенсификации развития научнотехнического процесса, она набирает обороты в своем развитии.

Это обстоятельство позволяет утверждать об усилении конкурентных позиций предприятий сферы услуг, а также о повышении их конкурентоспособности и усилении конкурентной борьбы. Для того чтобы организации сферы услуг обладали значительной степенью конкурентоспособности, реализовывали свои цели и задачи, развивались и имели возможность увеличивать рыночные доли на рынке услуг, им необходимо все свои стратегические цели и оперативные решения направлять на формирование и наращивание конкурентных преимуществ.

В этих условиях значительно усложняются расчеты эффективности деятельности предприятий. При осуществлении каких-либо проектов возможно увеличение стоимости их реализации, в следствие чего возникает риск отказа от продолжения дальнейшей работы в данном направлении, в связи с выявлением обстоятельств, приводящих к не возможности получения конечного результата и/или его значительного удорожания. Данная ситуация приводит к не желанию инвесторов финансировать предпринимательские проекты, и тем самым невольно тормозит экономическое развитие регионов. Эта проблема может быть успешно решена при развитии сферы страхования и страхового рынка.

Страхование является одним из наиважнейших элементов функционирования инфраструктуры рыночных отношений любой индустриально развитой страны, также субъектов, входящих в ее состав. Деятельность страховых компаний способна оказывать значительное влияние на экономику государства. Помимо того, что с государства может частично сниматься обязанность финансирования мероприятий по преодолению стихийных бедствий и других вредоносных последствий, страховые компании могут выступать в качестве крупных инвесторов.

Следует отметить, что вопросам конкурентной борьбы в сфере страхования посвящены труды А.А. Абагяна, С.А. Айвазяна, , НИ. Бурдакова, К.Г. Воблого, С Л. Ефимова, А. Зернова, И.В. Кузнецова, Е. Кургина, В.В. Лесных, В. Петрова, П. Серебровского, В. Смирнова, Г.И. Фалина, В.В. Шахова, С.Я. Шоргина, Э. Штрауба, Однако, данная тема, в настоящее время, приобретает не только научная, но и общественная значимость.

\section{РЕЗУЛЬТАТЫ И ИХ ОБСУЖДЕНИЕ}

В связи с данной общественной значимостью страхования у государства возникает обязанность не только в разработке и применении мер стимулирующих данную деятельность, но и необходимость осуществления ее контроля. Поэтому правоотношения, выделяемые при осуществлении страхования, неодно- 
родны. Их можно условно разделить на группы. В первую группу можно отнести непосредственно страховые правоотношения возникающие между страховщиком и страхователем (выгодоприобретателем, застрахованным лицом). В сфере осуществления страховой деятельности можно выделить и отнести во вторую группу отношения, сопутствующие страховым. Это деятельность посредников, осуществляющих продвижение страховых услуг страховщиков, представляющих интересы участников договора страхования, осуществляющих оценку страховых рисков и т.п. Это также отношения по поводу организации деятельности по страхованию, перестрахованию, взаимному страхованию. Особую группу составляют отношения, связанные с осуществлением государственного контроля и надзора за деятельностью страховщиков - профессиональных участников гражданского оборота [1].

Согласно мнениям российских экспертов - участников страхового рынка России, в настоящее время пристальное внимание разумной части страхового сообщества привлекает разработка Стратегии развития страхования на долгосрочную перспективу. Министерство финансов РФ готовит Стратегию развития страхования до 2020 года. Одновременно свой собственный проект Стратегии готовят представители страховщиков. У экспертов нет сомнений в том, что в процессе разработки Стратегии Минфин, как орган государственного управления, ответственный за подготовку окончательной версии Стратегии и внесение ее в правительство, будет учитывать мнения и предложения как страховщиков, так и других заинтересованных лиц [3].

Кроме того, с точки зрения опытных экспертов, российский рынок страхования уже вошел в первую фазу изменений, 2013 год - год принятия Стратегии, а затем ее внедрения. По их утверждению, совершенно безосновательно считать, что в России непрозрачные условия страховых продуктов. Сегодня страховщики максимально подробно расписывают все детали условий страхования, переводя тонны бумаги. Нельзя отрицать, что среди известных страховых компаний есть такие компании, которые играют такими условиями в свою пользу. Поэтому, как считает эксперт Сивков А.В. (заместитель председателя правления ОАО СК «Альянс»), необходимо выработать определенный стандартный набор условий, чтобы, например, покупая каско, потребитель точно знал, что именно туда включено. Этот вопрос, среди прочих, также обсуждался в ходе работы над Стратегией.

Следует также отметить, что по самым последним данным, опубликованным в прессе и на различных профессиональных порталах и сайтах, Правительство Российской Федерации концептуально поддержало проект стратегии развития страхового рынка до 2020 года. Такое заявление сделал журналистам заместитель министра финансов России Алексей Моисеев.

В 2012 году истек срок действия стратегии, которая была утверждена правительством в 2008 году. В конце октября 2012 года Минфин подготовил текст новой стратегии и направил его на согласование в ведомства. Документ был доработан по итогам обсуждения на межведомственном совете по страховой деятельности и внесен в правительство перед Новым годом, однако 
затем аппарат правительства вернул его в Минфин на доработку. В итоге проект стратегии был внесен в правительство в феврале текущего года $[3,4]$.

В целом, согласно экспертной оценке, российский страховой рынок нуждается в трансформации, что очевидно, но и утверждать, что экономическая ситуация носит негативный характер, тоже не правильно. Современное страховое сообщество вполне профессионально и квалифицированно, и его действия в области новых продуктов и раскрытия информации - достаточны, чтобы образованный человек, умеющий читать и писать, мог понять, от каких рисков он застрахован. Тем не менее, не исключены ситуации, когда встречаются отдельные недобросовестные люди и организации в банковской, промышленной, и в других сферах, но это уже вопрос их личной ответственности. По мнению Сивкова А.В. «Страховой рынок объективно - не самая плохая отрасль российской экономики, наша проблема в том, что мы сами любим говорить, какие мы плохие. Конечно, надо искать слабые точки, требующие развития, и над ними работать, но если мы сами себя уважать не будем - нас никто уважать не будет. Страховщики - это люди, которые действительно хорошо соображают, формируют резервы, делают сложнейшие актуарные расчеты, умеют работать с риском, принимать на страхование и перестраховывать самые трудные объекты, по которым, если что-то случиться, кроме страховщиков платить в сущности некому. Нам важно самим понимать, что мы несем очень большую ценность для экономики в целом и можем претендовать на создание в России одного из самых развитых страховых рынков в мире» [3].

Таким образом, учитывая особенности страхового рынка, следует сначала задаться вопросом об основных результатах деятельности страховых компаний за последние несколько лет, причем не только по официальным данным, публикуемым, к примеру, Федеральной службой страхового надзора Российской Федерации (ФССН России), но и оценить эти результаты с позиции потребителей, получающих страховые услуги.

Согласно данным Федеральной службы страхового надзора (ФССН России), за первое полугодие 2012 года страховые сборы по сравнению с аналогичным периодом прошлого года выросли на 24\% и составили 363,18 млрд. рублей. Одновременно отмечено увеличение объемов страховых выплат — на 31\%, до 200,03 млрд. рублей.

Основными точками роста страхового бизнеса, как и в последние два года, остается ипотека и страхование автогражданской ответственности. Так, по данным ЦБ РФ, в первом полугодии 2012 года выдача ипотечных кредитов возросла по сравнению с аналогичным периодом прошлого года на $60 \%$. Вместе с ростом кредитования под залог жилья равноценно увеличились и объемы ипотечного страхования.

Рост показателей 2012 года ценен прежде всего тем, что он не приукрашен и отражает реальную ситуацию на страховом рынке. Власти наконец-то очистили рынок от различного рода налогосберегающих схем. С 1 июля 2012 года вступили в силу поправки в закон «Об организации страхового дела». 
Теперь страховщики могут заниматься либо только страхованием жизни, либо всеми остальными видами страхования. Компаниям, занимающимся серыми схемами, сегодня на рынке места нет - усилия ФССН России по легализации страхового бизнеса увенчались успехом [2].

Согласно другим экспертным источникам, доля совокупных страховых премий, собранных десяткой компаний-лидеров в 2012 году, составила $57 \%$ по сравнению с 56\% годом ранее. Эти данные приведенные начальником управления экономического анализа и контроля за достоверной отчетностью субъектов страхового дела Федеральной службы по финансовым рынкам (ФСФР) Татьяной Майоровой публикуют в колонке «Страховые новости» аналитики профессионального страхового портала «Страхование сегодня».

Опираясь на представленные ФСФР данные, десять крупнейших страховщиков России в прошлом году собрали 461,5 млрд рублей премий и выплатили свыше 232 млрд рублей возмещений. Коэффициент выплат по десяти лидирующим страховщикам за 2012 год снизился на 1\% - с 51\% до 50\%, при этом в целом коэффициент по рынку за истекший год составил $46 \%$.

Доля десяти лидеров в общем объеме возмещений в 2012 году не изменилась по сравнению с 2011 годом и составила $63 \%$.

В частности, «Росгосстрах», занявший 1-е место, за прошлый год собрал 97,4 млрд рублей премии по всем видам страхования, а страховые выплаты группы составили 41,2 млрд рублей. Серебро по показателю сбора премий у компании «СОГАЗ» - 75,9 млрд рублей, размер выплат - 29,8 млрд рублей.

Третье место в десятке страховых организаций, лидирующих по сбору страховой премии за 2012 год, занимает «Ингосстрах» со сборами 67,8 млрд рублей и выплатами 43,8 млрд рублей.

На четвертом месте находится «РЕСО-Гарантия», собравшая 51,8 млрд рублей и выплатившая 28,3 млрд рублей. Пятое место по итогам прошлого года у «АльфаСтрахования» с премией в размере 34,1 млрд рублей и выплатами 14,9 млрд рублей. Далее в списке крупнейших по сборам страховых организаций находится ВСК (33,5 млрд рублей премии и 17,1 млрд рублей выплат), седьмую позицию занимает компания «Согласие» (сборы 33,3 млрд рублей и выплаты 19,4 млрд рублей).

Восьмая позиция досталась компании «Альянс» со сборами 25,1 млрд рублей и выплатами 15,3 млрд рублей, на девятом месте находится «ВТБ Страхование», собравшая 22,7 млрд рублей и выплатившая 7,5 млрд рублей, замыкает десятку лидеров страховая компания МСК со сборами 19,9 млрд рублей и выплатами 14,8 млрд рублей [3].

Тем не менее, не смотря на подобную оптимистичную информацию, не стоит делать преждевременных выводов относительно ситуации на страховом рынке. Опираясь на статистические данные ФССН России, представленные аналитическим отделом профессионального страхового портала «Страхование сегодня», позволяют провести более подробный анализ динамики развития страхового рынка России, с использованием рейтинга лидеров страхового 
рынка, являющихся самыми конкурентоспособными на сегодняшний день компаниями [3].

Таблица 1 - Концентрация страхового рынка по годам страхования.

\begin{tabular}{|l|l|l|c|c|c|c|c|}
\hline \multirow{2}{*}{$\begin{array}{c}\text { № } \\
\text { п/п }\end{array}$} & \multirow{2}{*}{ Название компании } & \multicolumn{5}{|c|}{ Поступления по годам, (\%) } \\
\cline { 3 - 8 } & & 2007 & 2008 & 2009 & 2010 & 2011 & 2012 \\
\hline 1 & РОСГОССТРАХ & 2,47 & 2,59 & 2,81 & 13,34 & 12,69 & 12,04 \\
\hline 2 & СОГАЗ & 6,18 & 6,96 & 7,59 & 8,61 & 8,27 & 9,39 \\
\hline 3 & ИНГОССТРАХ & 7,32 & 7,64 & 8,70 & 7,39 & 7,94 & 8,38 \\
\hline 4 & РЕСО-ГАРАНТИЯ & 6,66 & 5,46 & 5,93 & 6,43 & 6,76 & 6,41 \\
\hline 5 & АЛЬФАСТРАХОВАНИЕ & 2,19 & 3,08 & 3,76 & 3,67 & 4,74 & 4,22 \\
\hline 6 & ВСК & 3,68 & 3,98 & 3,81 & 4,51 & 4,25 & 4,15 \\
\hline 7 & СОГЛАСИЕ & 2,23 & 1,99 & 1,75 & 2,84 & 3,87 & 4,12 \\
\hline 8 & АЛЬЯНС & 4,82 & 3,97 & 3,86 & 3,70 & 3,24 & 3,09 \\
\hline 9 & ВТБ СТРАХОВАНИЕ & $\leq 1$ & $\leq 1$ & $\leq 1$ & 1,00 & 2,92 & 2,82 \\
\hline 10 & СТРАХОВАЯ ГРУППА МСК & 1,33 & $\leq 1$ & $\leq 1$ & 1,80 & 2,15 & 2,47 \\
\hline
\end{tabular}

Анализ данных по концентрации страхового рынка (таблица 1) позволяет утверждать, что рынок страховых услуг интенсивно развивается, объем поступлений страховых фирм увеличивается, что свидетельствует о нарастающих темпах использования страховых продуктов потребителями. Конечно часть этих продуктов потребители вынуждены приобретать в законодательном порядке, а не в силу естественной потребности в данном виде продукта. Но с другой стороны это обстоятельство успешно способствует не только развитию рынка страхования, но и стимулирует страховые компании предлагать новые продукты и использовать новые технологии для привлечения большего количества клиентов с целью повышения объемов продаж. Данное обстоятельство в свою очередь стимулирует конкурентную борьбу, заставляя руководство компаний создавать все новые и развивать имеющиеся конкурентные преимущества и дифференцировать свою деятельность от деятельности компаний конкурентов. А так как именно успешно осуществленная конкурентная стратегия является гарантом реализации стратегии развития компании, то руководство страховых компаний напрямую заинтересовано в усилении своих конкурентных преимуществ. Кроме того, поддержка государства в развитии страхового рынка и его заинтересованность в совместной разработке Стратегии развития страхования на долгосрочную перспективу позволит развиваться этому рынку с еще большей интенсивностью.

Также при анализе данных видно, что за последние три года на рынке страховых услуг произошло перераспределение по долям рынка, что также свидетельствует о мощной конкурентной борьбе, в которой, однако некоторые ее участники удерживают стабильные позиции в течение последних 6 лет, не смотря на тяжелый экономический кризис. При этом наблюдается смена лидера рынка и перераспределение конкурентной позиции последователей за лидером (таблица 1). 
Если сравнивать данные по концентрации страхового рынка (таблица 1) и динамику концентрации страхового рынка за период с 2007 по 2012 года (рисунок 1), то можно наблюдать стабильную положительную динамику роста страхового рынка России, что еще раз подтверждает мнение и прогнозы экспертов [3].

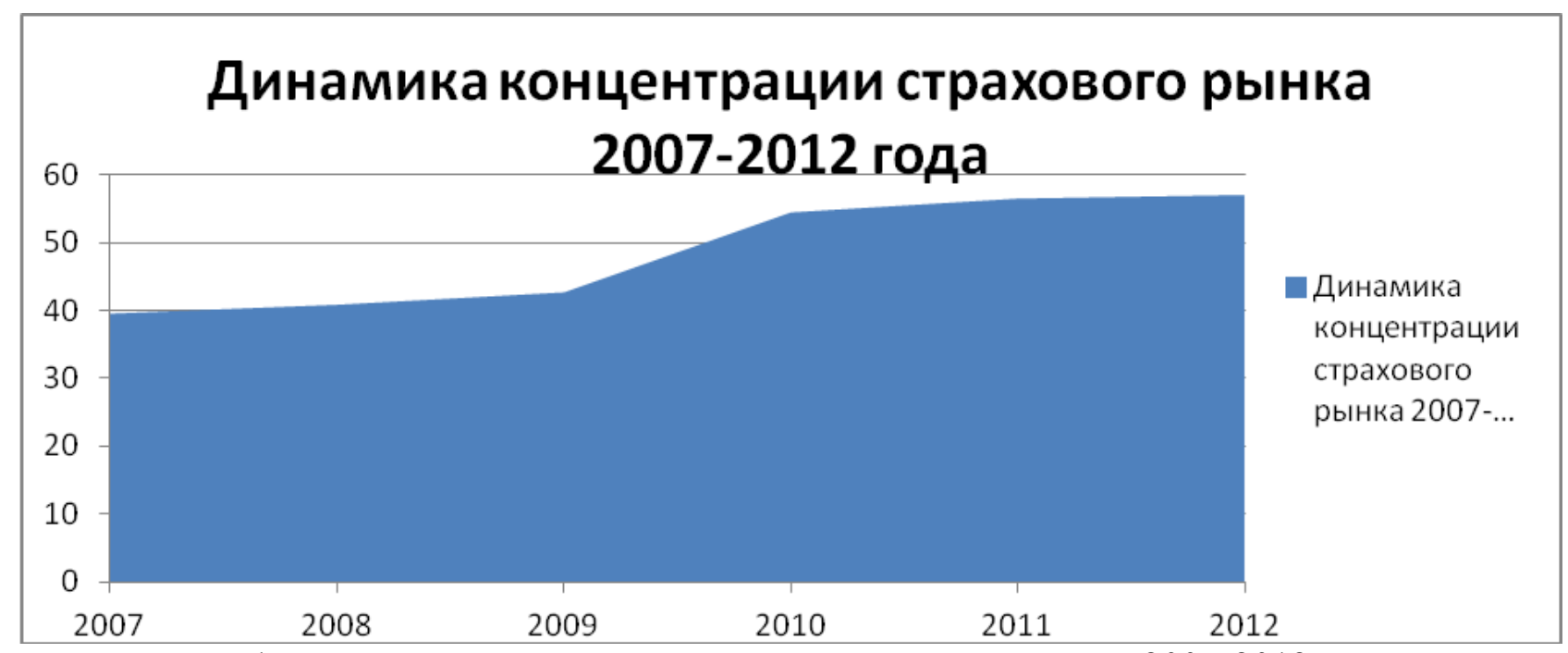

Рисунок 1 - Динамика концентрации страхового рынка России 2007-2012 года

Крайне важно при рассмотрении и анализе динамики страхового рынка, учитывать также и прогнозные данные, представляемые авторитетными экспертными агентствами в бизнес-среде, в частности страховании. Так, например, рейтинговое агентство «Эксперт РА» представляет следующие прогнозные данные развития страхового рынка на 2013 год.

«Прогноз динамики взносов на 2013 год был дан на основе двух сценариев - позитивного и негативного. Оптимистичный сценарий предполагает развитие ситуации в соответствии с базовым прогнозом МЭР (ценой на нефть в 97 долл. за баррель и ростом ВВП на $3,7 \%$ ). Негативный сценарий предполагает падение цены на нефть до 80-90 долл. за баррель, что может вызвать рецессию в экономике и проблемы в банковской системе.

Прогноз динамики страховых взносов основывался на следующих показателях:

7. прогноз социально-экономического развития Российской Федерации на 2013 год и плановый период 2014-2015 годов (МЭР);

8. прогноз объемов банковского кредитования на 2013 год ЦБ РФ;

9. прогноз продаж новых автомобилей на 2013 год АЕБ;

10. анализ исторических данных.

Все прогнозы даны в номинальном выражении без учета инфляции.

Показатели российского страхового рынка были рассчитаны на основе анализа финансовой отчетности за 9 месяцев 2012 года 83 страховщиков, специализирующихся на страховании ином, чем страхование жизни. В выборку вошли компании в основном из топ-100 российского страхового рынка, сум- 
марная рыночная доля которых по итогам 9 месяцев 2012 года превысила 75\% (с учетом входящего перестрахования).

По данным ФСФР, за 9 месяцев 2012 года по сравнению с 9 месяцами 2011 года темпы прироста взносов на российском страховом рынке составили 22\%. При этом квартальные темпы прироста взносов постепенно замедляются (25,7\% за 1-ый квартал, 22,9\% за 2-ой квартал, 20,7\% за 3-ий квартал). Таким образом, рынок развивается в соответствии с данным еще в конце 2011 года оптимистичным сценарием Эксперт РА» (прогноз темпов прироста взносов на 2012 год - 15-20\%). По итогам 2012 года объем взносов составит 800 млрд. рублей.

По прогнозам «Эксперт РА», в случае, если экономика будет расти в соответствии с базовым сценарием МЭР (оптимистичный прогноз), в 2013 году темпы прироста взносов составят порядка 17\%. Тогда совокупный объем взносов на российском страховом рынке достигнет 935 млрд. рублей.

В случае реализации негативного сценария (если цена на нефть опустится до 80-90 долл. за баррель), темпы прироста взносов в 2013 году составят 7\%. При этом совокупный объем взносов на российском страховом рынке не превысит 855 млрд. рублей.

Даже если реализуется негативный сценарий, падения взносов в 2013 году можно будет избежать. Во-первых, между динамикой всей экономики и страхового рынка существует лаг в полгода - 9 месяцев. Во-вторых, сокращение спроса на страхование частично нейтрализуется ростом стоимости страховой защиты в результате ослабления курса рубля. В-третьих, некоторый прирост рынку даст стимулирование спроса на страхование и введение новых обязательных видов страхования.

Прогноз динамики финансовых показателей предполагает реализацию базового (оптимистичного) сценария развития страхового рынка. В этом случае в 2013 году страховой рынок ожидает рост расходов на ведение дела и комбинированного коэффициента убыточности-нетто, незначительное повышение рентабельности инвестиций и, в результате, снижение рентабельности собственных средств. Снижению относительных показателей рентабельности собственных средств будет способствовать также рост капитала страховых компаний.

Ослабление курса рубля, ужесточение ответственности страховых компаний (распространение на страхование закона «О защите прав потребителей», неоднозначные решения ВАС об УТС и исключениях из покрытия) приведут к росту выплат страховых компаний. При этом страховщики скорее всего не решатся на заметное увеличение тарифов в связи с замедлением темпов роста взносов, чтобы не оказаться вновь в ловушке ликвидности. В результате в 2013 году следует ожидать роста комбинированного коэффициента убыточности-нетто, значение которого даже с учетом суброгации превысит 100\%.

В 2012 году рентабельность инвестиций страховых компаний находится на стабильно низком уровне. В первую очередь это связано с невысокими ставками по банковским депозитам. В 2013 году с ухудшением условий заимствования как за рубежом, так и на внутреннем фондовом рынке, банки все больше будут 
заинтересованы в привлечении средств физических лиц. В результате продолжится рост ставок по депозитам, начавшийся с осени 2012 года. Тем не менее, рост будет скромный из-за ужесточения банковского регулирования. Так с 1 марта 2013 года Банк России получит право напрямую ограничивать ставки по депозитам. По прогнозам «Эксперт РА» среднее значение показателя рентабельности инвестиций страховых компаний составит 6-7\%.

По базовому прогнозу «Эксперт РА», в 2013 году совокупный объем взносов на российском страховом рынке достигнет 920-945 млрд. рублей (прирост на 15-18\%). Этот прогноз предполагает рост экономики в соответствии с базовым сценарием МЭР. В случае реализации негативного сценария (если цена на нефть снизится до 80-90 долл.), темпы прироста взносов в 2013 году составят 5-10\%. При этом совокупный объем взносов на российском страховом рынке не превысит 840-880 млрд. рублей. По итогам 2012 года объем взносов составит 800 млрд. рублей (прирост - 20\%)» [5] .

Не менее интересными в данном контексте могут быть результаты маркетинговых исследований, проводимых экспертами. Так «Эксперт РА» опубликовало данные собственного маркетингового исследования, проводимого среди представителей топ-менеджмента страховых компаний. В результате этих исследований агентство получило интересные данные по ожиданиям перспектив со стороны страховщиков относительного развития страхового рынка.

В результате проведенных исследований выяснилось, что страховщики ждут от государства не столько прямого стимулирования спроса, сколько создания условий для нормальной работы. До 40\% опрошенных руководителей страховых компаний считают важнейшим разделом стратегии отрасли повышение эффективности бизнеса и увеличение национальной емкости. Особое вмешательство государства требуется для развития страхования жизни, регулирования страховых агентов и увеличения емкости рынка. От ФСФР в первую очередь ожидают повышения прозрачности и предсказуемости (этот вариант ответа выбрали 45\% участников голосования), от ФАС - борьбы с демпингом (46\%). При этом страховщики надеются на самостоятельное решение некоторых проблем рынка (за счет стандартизации и формирования баз страховой статистики). 38\% участников опроса считают ключевой мерой стимулирования спроса на страхование повышение надежности и эффективности страхового рынка. Более половины участников опроса выступают за введение налоговых льгот в страховании жизни, еще $20 \%$ - за подключение страховщиков к пенсионной системе. Страховщики ожидают решительных действий государства также в сфере регулирования страховых посредников. В борьбе за эффективность и доверие страхователей страховщики надеются больше на себя, чем на государство. Более половины опрошенных уверены, что существенное повышение эффективности работы страховых компаний возможно за счет формирования баз данных страховой статистики. Половина опрошенных представителей страхового сообщества уверена, что повысить доверие к страховой отрасли можно за счет стандартизация правил 
страхования и/или порядка урегулирования убытков. Лишь каждый пятый участник опроса считает наиболее действенной мерой создание института страхового омбудсмена [5].

\section{ВЫВОДЫ}

Подводя итоги и обобщая выводы по предложенной тематике, можно сказать пару слов и о проблемах страхового рынка, которых здесь в целом нем меньше, чем на любом другом рыночном секторе экономики. Спектр данных проблем достаточно обширен, а причины, по которым данные проблемы возникают, еще более многочисленны, начиная от низкого уровня заинтересованности потребителей в страховых услугах и заканчивая несовершенной государственной политикой в области страхования. Тем не менее, руководители-энтузиасты, настоящие профессионалы и «кузнецы» своего дела не позволяют сложностям и проблемам взять верх над перспективами и возможностями дальнейшего развития страхового рынка.

Отсюда, учитывая все выше изложенное, можно предложить следующее: во-первых, усилить сотрудничество государственных органов управления страхованием и страховых компаний при разработке Стратегии развития страхования на долгосрочную перспективу; во-вторых, усилить меры и способы государственной поддержки и государственного регулирования деятельности страховых компаний, с целью недопущения монополизации страхового рынка отдельными компаниями; в-третьих, совершенствовать методы контроля и надзора за деятельностью страховых компаний, с целью выявления недобросовестных страховщиков, подрывающих доверие потребителей; вчетвертых, развивать инновационные технологии в страховании, обеспечивающие победу в конкурентной борьбе. Все это вкупе возможно приведет к более интенсивному развитию страхового рынка России.

\section{ЛИТЕРАТУРА}

1. Ефимов, С.Л. Деловая практика страхового агента и брокера / С.Л. Ефимов - М.: Юнити 2009.- 421с.

2. Гейц, И.В. Расчеты по средствам социального страхования / И.В. Гейц Санкт-Петербург: «Дело и Сервис», 2012.- 160 с.

3. Профессиональный страховой портал «Страхование сегодня» [эл.ресурс] / Режим доступа: http://www.insur-info.ru/statistics/ и http://www.insurinfo.ru/interviews/ (Дата обращения: 15.03.2013)

4. Официальный сайт Всероссийского союза страховщиков (ВСС) [эл.peсурс] / Режим доступа: http://www.ins-union.ru/ (Дата обращения: 15.03.2013)

5. Официальный сайт рейтингового агентства «Эксперт РА» [эл.ресурс] / Режим доступа: http://www.raexpert.ru/(Дата обращения: 15.03.2013) 